\title{
Prior residence, territory quality and life-history strategies in juvenile Atlantic salmon (Salmo salar L.)
}

\author{
C. J. Cutts* $*$, B. Brembs $\dagger$, N. B. Metcalfe* and A. C. Taylor* \\ *Fish Biology Group, Graham Kerr Building, Institute of Biomedical and Life Sciences, \\ University of Glasgow, Glasgow, G12 8QQ, U.K. and †Department of Genetics, \\ Theodor-Boveri Institute for Biosciences, Am Hubland, D-97074 Wuerzburg, Germany
}

(Received 16 December 1998, Accepted 15 June 1999)

\begin{abstract}
Three groups of juvenile salmon were introduced sequentially into an artificial stream to investigate the effects of prior residence on behaviour and territory choice. Almost half of the first group obtained and defended distinct territories, the other half being constrained to an area approximately the size of one large territory. All of the fish in the subsequent groups, bar one, were also constrained to the same site. Since the fish were of similar size, prior residence alone seemed to influence which individuals obtained territories. However, within the first group, the fish that obtained territories were larger and more aggressive. The territorial fish did not appear to choose the most profitable territories, although they had the greatest opportunity to do so. Since juvenile salmon emerge from their gravel nests fairly synchronously, a time constraint on site sampling is hypothesised: there may be a risk in taking time to sample sites, since these same sites may become occupied with conspecifics. However, fish with territories fed at faster rates than non-territorial fish, possibly because of reduced competition for prey items. Consequently, fish from the first group (containing most of the territorial fish) grew faster than the other two groups. Moreover, most of the territory holders, but only one of the non-territorial fish, reached the threshold size that increases their probability of smolting the following year. This suggests that ability to obtain a defensible territory, primarily through prior residence, influences the age at which juvenile salmon can migrate to sea.
\end{abstract}

(C) 1999 The Fisheries Society of the British Isles

Key words: Atlantic salmon; prior residence; territoriality; aggression; life-history strategies.

\section{INTRODUCTION}

It is well known that differences in competitive ability in territorial species have major short- and long-term consequences. Even in the absence of strict territories, individuals of high status in a dominance hierarchy and good competitive ability may obtain preferential access to resources, such as food or mates, have a higher survival rate (Huntingford \& Turner, 1987), and higher growth rates (Metcalfe et al., 1989, 1990). Juvenile Atlantic salmon, Salmo salar L. have been studied extensively in this respect. Together with other salmonids, their life history is highly plastic (Thorpe, 1989). Within a single year class of juvenile salmon wide discrepancies in growth rate soon occur, in as little as four months after emergence. Juvenile salmon exceeding a threshold growth rate by August of their first year will metamorphose into the marine smolt phase the following spring, forming an upper modal group (UMG), whereas slower growing salmon (the lower modal group, LMG) will defer metamorphosis for up to 8 years (Thorpe, 1977, 1989; Metcalfe \& Thorpe, 1990).

$\$$ Present address and author to whom correspondence should be addressed: University Field Station, Rowardennan, Glasgow G63 0AW. Tel.: +44 (0)1360 870271; email: cjc3r@udcf.gla.ac.uk 
It has been shown that relative dominance and competitive ability of juvenile salmon in the first few months post-emergence influence subsequent life-history strategies through their effect on growth rates (Metcalfe et al., 1989, 1990; Metcalfe, 1991). Juvenile salmonids in general are territorial, and work on other salmonids such as brown trout, S. trutta L. has shown that the inability of a young salmonid to acquire a feeding territory will result in a forced emigration downstream, resulting either in taking up inferior feeding sites or in starvation (Elliott, 1984, 1990). The consequences of differences in competitive ability are therefore well understood.

In salmonids, a confounding variable in elucidating any links between individual aggressive and foraging behaviour and subsequent success is prior residence on a territory. Juvenile Atlantic salmon exhibit a normally distributed temporal pattern of emergence from both their natural spawning grounds and from artificial redds (Gustavson-Marjanen \& Dowse, 1983; Brännäs, 1987) with a duration of approximately 2 weeks, although the majority tend to emerge synchronously over a three-night period (Gustavson-Marjanen \& Dowse, 1983). Early emerging juveniles are competitively superior to their later emerging conspecifics, by being first to acquire the available territorial space, and are also larger by the time other juveniles emerge (Mason \& Chapman, 1965; Chandler \& Bjornn, 1988; Metcalfe \& Thorpe, 1992). Such differences in competitive ability due to relative time of emergence obscure intrinsic differences in competitive ability (Cutts et al., 1999; Johnsson et al., 1999).

Many previous studies of salmonid behaviour have taken place in laboratory tanks, and are unrealistic in that fish may not be setting up true territories as would occur under natural conditions. Therefore this study presents data on the behavioural mechanisms conferring dominance in salmon fry in the semi-natural setting of an artificial stream. The effects of prior residence on subsequent behaviour and success was also tested, by releasing groups of salmon into the stream sequentially. The study also examined which individuals obtained which territories within each group of introduced fish, given the virtually untested assumption that the best territories will go to individuals of highest rank (Maynard Smith, 1974). Although Fausch (1984) and Hughes (1992) have shown that highest ranking individuals owned territories with the highest resource level, it was unclear whether owning a high-quality territory was a consequence of dominance or its cause.

\section{MATERIALS AND METHODS}

The fry were $0+$ full siblings, previously reared under hatchery conditions at the University Field Station, Rowardennan, Scotland. The three groups were sampled randomly from a single tank, and due to mortalities over time, consisted of unequal numbers of salmon $(14,17$, and 11 respectively). The groups were introduced into the artificial stream exactly seven days apart in order of group number. As a consequence, the fish in the three groups were of similar size at any one time but differed in average size at the time each was introduced to the stream: mean folk lengths at the time of introduction were $52.2 \pm 0.9$ (s.E.) $\mathrm{mm}$ (group 1), $53.1 \pm 0.7 \mathrm{~mm}$ (group 2), and $57 \cdot 0 \pm 1 \cdot 2 \mathrm{~mm}$ (group 3) (ANOVA: $F_{(2,39)}=7 \cdot 13, P<0 \cdot 005$ ). Since the fish were selected randomly from the original holding tank, and were being introduced to a novel environment, it was hoped that previous experience would not affect their interactions in 
the artificial stream. Fish were marked on both sides with unique combinations of alcian blue dye spots to aid individual identification.

The artificial stream was U-shaped and $0.55 \mathrm{~m}$ wide, with the arms being $3 \mathrm{~m}$ long, and was homogeneously landscaped with gravel (mean diameter of gravel $=0.03 \pm 0.02 \mathrm{~m}$ ) and small pebbles (mean diameter of pebbles $=0.10 \pm 0.03 \mathrm{~m}$ ) into an identical series of pools and riffles to simulate a stream setting, with each arm consisting of three pools separated by two riffles. The depth of each pool was $0.28 \mathrm{~m}$, with a mean water velocity of $0.11 \pm 0.01 \mathrm{~m} \mathrm{~s}^{-1}$. The two riffles were situated $1 \mathrm{~m}$ apart, and were $0.19 \mathrm{~m}$ deep, with a mean water velocity through them of $0 \cdot 15 \pm 0.01 \mathrm{~m} \mathrm{~s}^{-1}$. The U-bend of the stream consisted of a long $(1.25 \mathrm{~m})$ pool with a depth of $0.28 \mathrm{~m}$ and a mean water velocity of $0 \cdot 11 \pm 0 \cdot 001$ (S.E.) $\mathrm{m} \mathrm{s}^{-1}$, with an identical gravelled substratum to that of the arms. The total surface area of the artificial stream was $4 \mathrm{~m}^{2}, 0.69 \mathrm{~m}^{2}$ of the total area situated in the U-bend. The artificial stream was partitioned into $0 \cdot 1-\mathrm{m}$ wide strips along its length using marks on the inner glass-sided wall and the opposite opaque wall. This enabled the observer to read positions of fish in terms of zones individually numbered from the upstream end, and subsequently to estimate the areas of any territories. Each zone was $0.06 \mathrm{~m}^{2}$ in area, and territory size was established by the number of zones actively defended by the fish.

Frozen Daphnia were thawed out in a reservoir above the most upstream part of the artificial stream. The reservoir received a constant slow inflow of water and overflowed into the artificial stream, maintaining a relatively constant, low influx of prey items into the water. The reservoir was replenished thrice daily with frozen Daphnia, after each observation session.

Three 1-h behavioural observations of the fish were made every day within the time periods $0900-1200,1400-1700$ and 1800-2000 hours for the duration of the experiment (August to October 1994, a total of 60 observation days and 180 observations). Observations consisted of recording during a single scan sample the zone occupied by each fish; then the rate of aggression was measured by observing each fish in turn for a one minute period and recording the number of interactions and the identities of the attacking and attacked fish. Aggression was defined as charges towards a conspecific; repeated charges were counted as separate incidents. Charges are defined as rapid, direct and unambiguous motions towards another fish (Abbott et al., 1985). This method was chosen because the fish initiating aggression invariably won, the attacked fish swimming away from the aggressor, and because charges are less ambiguous than other interactions, such as displaying. The rate of aggressive interactions was standardized by dividing the number of aggressive interactions by the number of fish present, giving aggressive interactions fish ${ }^{-1} \mathrm{~min}^{-1}$. However, to give a better idea of actual dominance, the number of attacks received fish ${ }^{-1} \mathrm{~min}^{-1}$ was subtracted from aggressive interactions fish $^{-1} \min ^{-1}$, giving net aggression. Individual feeding rates were also measured: each fish was observed for $1 \mathrm{~min}$ per observation session and the number of movements towards food recorded as feeding attempts (attempts $\min ^{-1}$ ).

Fish were removed and anaesthetized once every 2 weeks to be weighed (to the nearest $0.01 \mathrm{~g}$ ) and fork lengths measured (to the nearest $0.1 \mathrm{~mm}$ ), and were then allowed to settle for $24 \mathrm{~h}$ after replacement before any further behavioural observations were taken. Weight data were used to calculate weekly specific growth rates (percentage change per day).

Once the favoured feeding positions of the fish were established, defined as the position where each individual fish spent the greatest percentage of its time, the quality of these positions was assessed by catching prey drift in a mesh net $(15 \times 20.5 \mathrm{~cm})$ suspended in the middle of the water column for 5 min (after removing the fish from the artificial stream). The sampled prey were dried out and the dry weight of food passing each point per minute calculated. The depth of the net was always less than the depth of the water column, but by measuring each site three times (in the same way) it was hoped that the final profitability value was representative of each site. Water velocity at the same sampling site was measured with an Ott flow-meter, giving a value of site profitability in $\mathrm{mg}$ of prey $1^{-1}$. In this way, it was estimated that there was $0 \cdot 015 \pm 0 \cdot 001$ (=S.E.) $\mathrm{mg}^{-1}$ of prey (dry weight) in the artificial stream at any one time. Due to the relative 


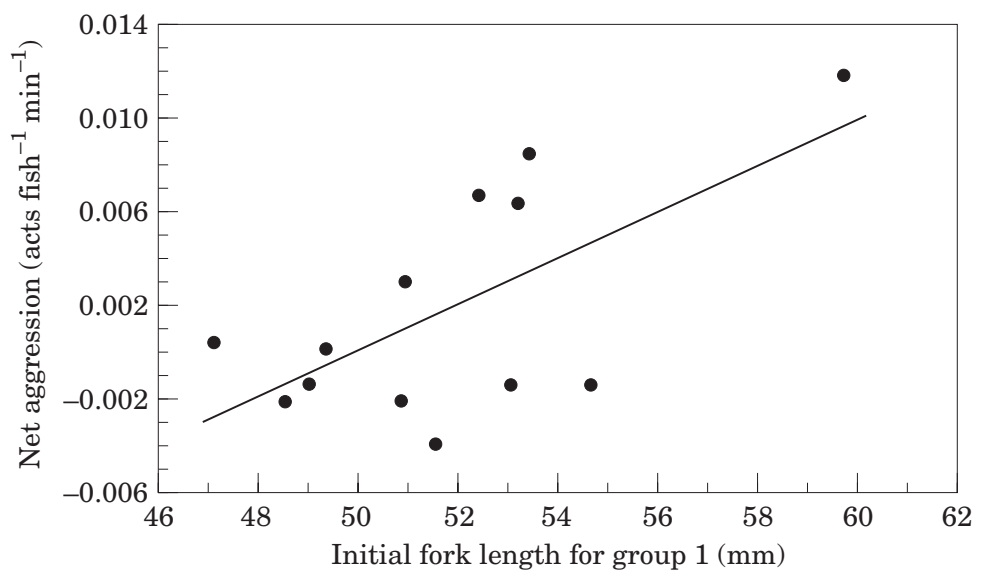

FIG. 1. The relationship between initial size (fork length, $\mathrm{mm}$ ) and net aggression (acts fish ${ }^{-1} \mathrm{~min}^{-1}$ ) for group 1 fish.

homogeneity of the substrate, and the consistency of the lighting, it was hoped that measuring food alone would give an idea of territory quality, since other aspects of quality, such as shade and cover, were fairly invariant between sites.

\section{RESULTS}

Of the 14 fish introduced in group 1, six subsequently defended large territories [mean area, based on the number of zones defended $=0.50 \pm 0.06$ (S.E.) $\mathrm{m}^{2}$ ]. The remaining eight fish were constrained to one riffle area, also $0.50 \mathrm{~m}^{2}$ in area. From the next two introduced groups (17 and 11 fish respectively), only one fish from group 2 obtained a territory, also $0.5 \mathrm{~m}^{2}$ in area. Thus once all the groups had been introduced, only seven fish were in possession of large territories, and a disproportionate number of these $(n=6)$ belonged to group 1 (goodness of fit test: $\chi^{2}=10 \cdot 54,2$ d.f., $\left.P<0 \cdot 01\right)$. As the artificial stream prevented any emigration, the remaining 35 fish were all constrained to the same riffle, where the maximum area defended by one fish was $0.03 \mathrm{~m}^{2}$. Since these fish were so constrained (due to the physical limitations of the artificial stream), they maintained individual distances aggressively, rather than distinct territories. Therefore these fish are termed non-territorial while those defending areas of $>0.40 \mathrm{~m}^{2}$ are termed territorial.

Of the fish in group 1, those obtaining a territory were significantly larger than the non-territorial fish (fork length of territory holders $=55 \cdot 08 \pm 1 \cdot 12 \mathrm{~mm}(n=6)$; non-territorial fish $=50 \cdot 11 \pm 0.67 \mathrm{~mm}(n=8)$, ANOVA; $\left.F_{(1,12)}=16 \cdot 34, P<0 \cdot 005\right)$. Larger fish in group 1 tended also to be more aggressive than smaller fish, in that they initiated more attacks than they received $\left(r^{2}=0 \cdot 219, n=13, P<0 \cdot 05\right.$, Fig. 1$)$. While this was partly due to territorial fish being significantly more aggressive than their counterparts (mean net aggression of territory holders and nonterritorial fish was $0.005 \pm 0.002$ (=S.E.) acts fish ${ }^{-1} \min ^{-1}(n=7)$ and $-0.001 \pm 0.001$ acts fish $^{-1} \min ^{-1}(n=35)$ respectively, Mann-Whitney $U$ test: $U=7 \cdot 00, P<0 \cdot 05)$, there was also a relationship between size and aggression in non-territorial fish (see later). 


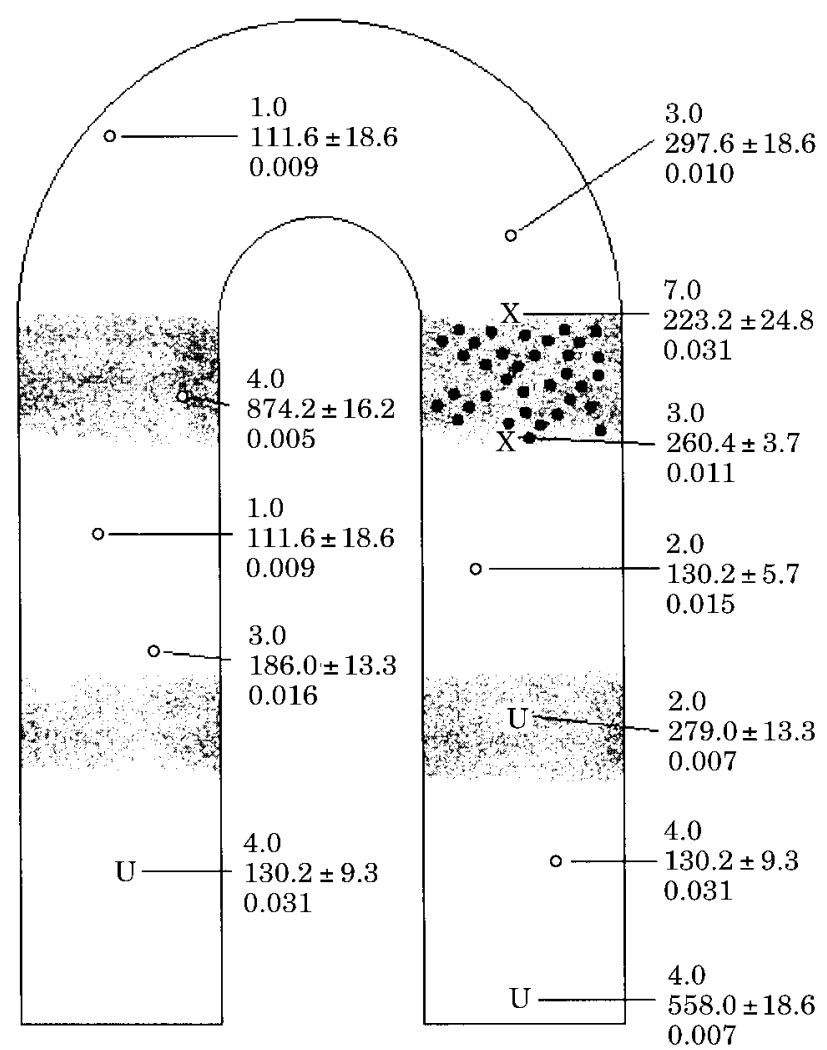

FIG. 2. Diagram of the artificial stream. The grey areas denote riffles in the stream, and water flowed from the left arm to the right. The corresponding three numbers to each sampling site $(\bigcirc$, territory holder's position; 0 , non-territory holder's position; X, sites up- and downstream of nonterritorial fish; U, unoccupied sites) represent, from top to bottom: dry weight $(\mathrm{mg}) \mathrm{min}^{-1} \pm 1 \cdot 0$ (s.E.) of food sampled, water velocity $\left(1 \mathrm{~min}^{-1}\right) \pm$ S.E., and dry weight of food per litre $\left(\mathrm{mg} \mathrm{l}^{-1}\right)$ respectively. See text for dimensions of the artificial stream.

To investigate whether those fish from group 1 that obtained territories chose superior sites, 12 sites along the artificial stream were sampled for prey drift and water velocity (Fig. 2). Sites represented by an open circle correspond to a territory holders' position, the sampling net being held at the point most frequently occupied by the territory holder. The sites marked ' $\mathrm{X}$ ' correspond to upstream and downstream of the riffle area occupied by $83.3 \%$ of the fish (marked by closed circles), and sites marked ' $U$ ' were unoccupied. Using the dry weight of food collected per minute per litre of water flowing past the site as a measure of territory quality, there were no significant differences in quality between the six sites the territory holders in group 1 chose as territories and the six other sites (mean quality of territories $=0.014 \pm 0.003 \mathrm{mg} \mathrm{l}^{-1} \quad(n=6)$, mean quality of remaining sites $=0.017 \pm 0.006 \mathrm{mg}^{-1}(n=6)$, ANOVA; $F_{(1,10)}=0 \cdot 40$, $P=0.541)$. This is despite six out of the seven territorial fish belonging to group 1 , and therefore having the greatest opportunity to sample various sites.

However, territory holders did benefit from a greater food intake. Fish with territories fed at a significantly greater rate than non-territorial fish (territory holders $=6 \cdot 33 \pm 1 \cdot 11$ feeding movements fish ${ }^{-1} \min ^{-1}$ ( $n=7$ fish, each observed 


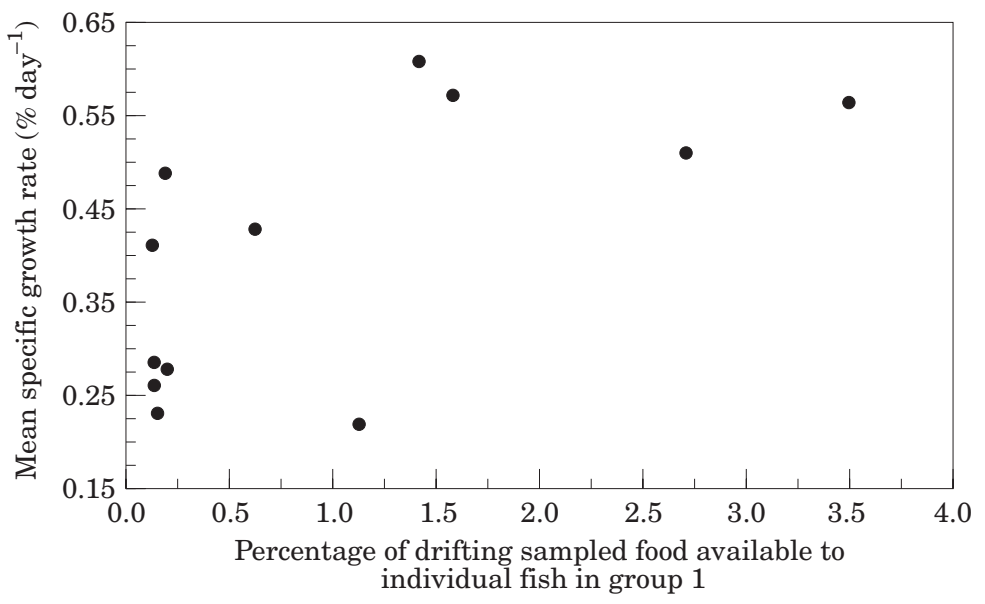

FIG. 3. The relationship between the percentage of the total food potentially available to individual fish and their mean specific growth rate $\left(\%\right.$ day $\left.^{-1}\right)$ in group 1.

an average of 90 times), non-territorial fish $=4 \cdot 58 \pm 0 \cdot 33$ feeding movements fish $^{-1} \min ^{-1}$ ( $n=35$ fish, observed a mean of 90 times); ANOVA: $F_{(1,37)}=3 \cdot 64$, $P=0 \cdot 05)$. This may be due to the monopoly on food items that each territory holding fish will have; despite no apparent preference for the best sites, territory holders had exclusive access to a large foraging area. Conversely, each of the non-territorial fish on the riffle had to share an area similar in size to a territory with 34 competitors. By recording the positions of fish, the percentages of total drift available to that position (assuming that all drift was available for consumption by the fish; Fig. 2) and the percentage of that drift available to individual fish after correction for the number of neighbouring fish also exploiting the same site, it was possible to test whether territorial fish benefited from their exclusive access to a food supply. In group 1, growth rate increased significantly with the percentage of food available to individual fish (Spearman Rank correlation, $r_{\mathrm{S}}=0 \cdot 639, n=14, P<0 \cdot 05$; Spearman rank correlation was used since most of the fish had relatively little access to food, thus skewing the data; Fig. 3). Analysis was restricted to group 1 fish, since they experienced the same initial conditions and were very similar in initial size. They also experienced the largest variation in food availability, since most of the territorial fish came from this group.

Despite the majority of fish being constrained to the riffle, there seemed to be a distinct hierarchy within this group of non-territorial fish. During each observation session, positions of individual fish within the group were recorded in terms of whether they were at the front, middle or back of the riffle. In this way the percentage of time spent by fish in these positions could be estimated; the front of the riffle was assumed to be the preferred feeding station. Net aggression correlated with initial fork length for the fish on the riffle $\left(r^{2}=0 \cdot 095, n=35\right.$, $P<0 \cdot 05$; Fig. 4). Initial fork length was the fork length ( $\mathrm{mm})$ of the fish from all three groups measured on the day group 3 was introduced, to remove any bias of using fork lengths for groups 1 and 2 measured prior to the introduction of group 3. Initially larger fish also spent significantly more time at the front of the 


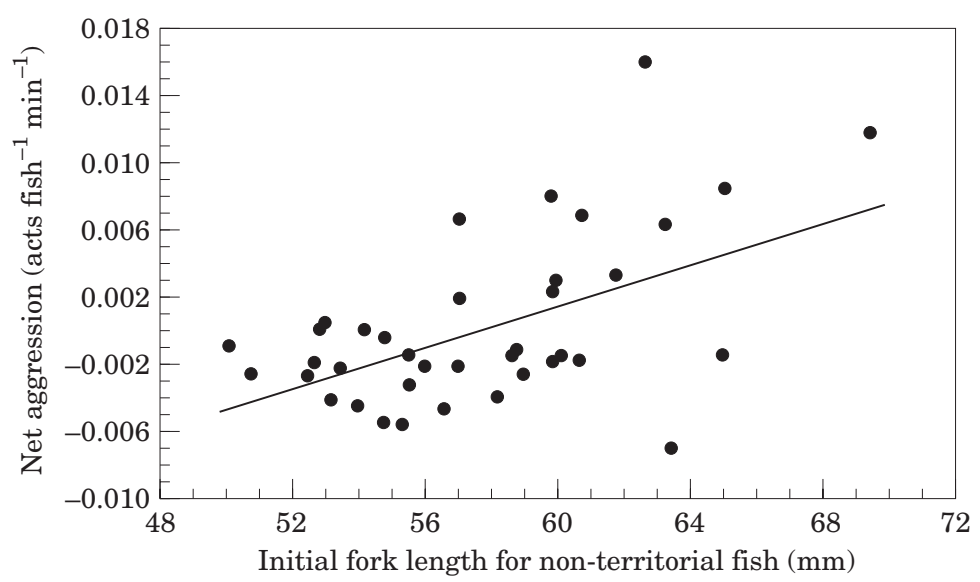

FIG. 4. The relationship between initial fork length $(\mathrm{mm})$ and subsequent net aggression (act fish ${ }^{-1}$ $\min ^{-1}$ ) for non-territorial fish.

riffle (measured as a percentage) than small ones [Spearman rank correlation (since percentage data was used): $\left.r_{\mathrm{S}}=0 \cdot 415, n=35, P<0 \cdot 05\right]$, presumably as a consequence of their greater aggression.

Group 1 on the whole grew faster $\left[0 \cdot 41 \pm 0.05\right.$ (S.E.) $\%$ day $\left.^{-1}\right]$ than the other two later-arriving groups $\left(0.34 \pm 0.04\right.$ and $0.26 \pm 0.06$ day $^{-1}$, respectively), presumably due to a prior residence effect, whereby they were more likely to obtain territories (one-way ANOVA between groups: $F_{(2,30)}=2 \cdot 70, P=0 \cdot 05$; Tukey post-hoc comparison of means shows a significant difference $(P=0 \cdot 05)$ between groups 1 and 3). However, there were no significant differences in growth rate between the groups when the territorial fish were removed from the analysis (mean specific growth rate of non-territorial fish: group 1 $=0.34 \pm 0.04 \%$ day $^{-1}$, group $2=0 \cdot 33 \pm 0 \cdot 04 \%$ day $^{-1}$, and group $3=0 \cdot 26 \pm 0.06 \%$ day $^{-1}$. ANOVA: $\left.F_{(2,24)}=0 \cdot 74, P=0 \cdot 487\right)$.

At the end of the experiment in October, six fish had a fork length of $>75 \mathrm{~mm}$ and so had a higher probability of undertaking the smolt transformation in the spring and migrating to sea (Thorpe, 1977). Five of these salmon were from the group of six surviving territory holders, compared with only one out of 35 non-territorial fish.

\section{DISCUSSION}

Almost half of the first group of introduced fish obtained and defended large territories, the remaining fish in the group being constrained to an area approximately the size of one large territory, along with almost all of the fish from the subsequent two groups. Although the specialized nature of the artificial stream along with the physical size and duration of the experiment precluded replication, the present study illustrates (in a semi-natural setting) that prior residence affects the outcome of intraspecific interactions. Similar findings have been documented for other species of salmonid in artificial streams: first emerging coho salmon fry, Oncorhynchus kisutch (Walbaum) had settler's rights to the environment and created and maintained a size gap between themselves 
and later emerging fry, although size at emergence between early and late fish was quite uniform (Mason \& Chapman, 1965). Moreover, the first juvenile rainbow trout, $O$. mykiss (Walbaum) introduced to an artificial stream also established a permanent size gap compared with later introductions of trout (Chandler \& Bjornn, 1988). Prior residence also affects interspecific interactions: a similar phenomenon was documented between Atlantic salmon and brown trout in the wild (Egglishaw \& Shackley, 1973), between chinook salmon, O. tshawytscha (Walbaum) and brown trout (Glova \& Field-Dodgson, 1995), and between coho salmon, brook trout, Salvelinus fontinalis (Mitchill), and brown trout (Fausch \& White, 1986). However, these studies used longer time intervals between early and late fish, e.g. 22 days in both Mason \& Chapman (1965) and Chandler \& Bjornn (1988). This gave fish time to create a size advantage. In this study the time intervals were much shorter: 7 days between each group, 14 days in total for all the fish to be introduced. All fish were of similar size, showing that prior residence alone, and not the size advantage it may subsequently confer, has a strong influence on which individuals obtain territories. Therefore prior residence, and with it information about the territory's resource value, is reflected in the increased competitive ability of the fish (Cutts et al., 1999).

Across all groups, aggression correlated significantly with size. In salmonids, there is often a clear correlation between status and size (Jenkins, 1969), and dominant fish tend to hold the most profitable positions (Fausch, 1984). However, it is unclear whether increased aggression is a consequence of territory ownership or a cause; increased aggression on establishing a territory has been described in the competitive threat hypothesis (Dill, 1978; Abbott et al., 1985). Moreover, most studies are based on observations of already established territory holders, and cannot disassociate the effects of territory quality and phenotypic quality on an individual's behaviour. However, there seemed to be a distinct hierarchy within the non-territorial fish: larger fish were more aggressive and spent more time at the upstream end of the riffle (the preferred feeding site; Fausch, 1984). This relationship persisted in the absence of actual territory ownership, suggesting that increased aggression was not a consequence of larger fish obtaining territories in group 1 , but a cause.

Although the larger, more aggressive fish in group 1 did obtain and defend large territories, they did not appear to choose the most profitable sites in terms of water velocity and particulate drift, as has been documented before in several studies (Fausch, 1984; Grant, 1990). These earlier studies provided evidence for the assumption that higher quality individuals will obtain territories, and the best territories will belong to those of highest rank (Maynard Smith, 1974; Arcese, 1989). However, in these studies the competitors had prior knowledge of the potential territories, so that superior competitors could exploit the best territories as they became vacant (Stamps \& Krishnan, 1994). In the present experiment the fish had no knowledge of potential territory quality before introduction to the artificial stream. Consequently, there may be a cost in searching for the best territory; with no prior knowledge of the environment there may be a risk in taking time to sample sites, as these sites may at the same time become occupied and defended by conspecifics. A similar conclusion was made in a study on pied flycatchers, Ficedula hypoleuca (Slagsvold et al., 1988), 
where the synchronous arrival of competing females on breeding grounds in spring results in their showing a pattern of restricted searching for mates, as it is very important to start breeding as soon as possible, for a delay in breeding means a reduction in reproductive success (Harvey et al., 1985). Similarly, after emergence, juvenile salmon are all searching for territories at approximately the same time, due to fairly synchronous emergence (Gustavson-Marjanen \& Dowse, 1983); this may also curtail sampling time. Moreover, in salmonids the social structure can be very stable for months after territory acquisition (Jenkins, 1969), so it will not be in an individual's best interests to risk failure to secure a territory due to sampling time. This may explain why territorial fish in group 1 failed to exploit the most profitable sites (in terms of food), despite having the greatest sampling opportunity (and the least competition).

However, although territorial fish did not occupy superior sites, they did feed at significantly greater rates than fish constrained to the riffle, although the difference between mean feeding rates was small. This concurs with previous studies (Grant, 1990) in which, by keeping neighbours farther away, the aggressive territorial fish decreased competition for drifting prey and increased their own feeding rate. Conversely, the 34 non-territorial fish were constrained to an area similar in size to one large territory and suffered a depressed feeding rate as a result. Furthermore, territorial fish benefited from their exclusive access to a food supply: group 1 fish grew faster if they had a greater exclusivity to passing prey items, territorial fish having the most exclusive access to food. This complements earlier studies whereby more aggressive fish have a higher gross gain rate than less aggressive fish (Puckett \& Dill, 1985; Grant, 1990). However, the difference in feeding rates was small: non-territorial fish may also have benefited from the anti-predator dilution effect of a larger group size, and foraged less cautiously as a result.

The mean growth rates of group 1 fish were higher than those of the other two groups, due to the territorial fish mostly belonging to this group. This complements an earlier study on the same species that also showed experimentally induced differences in arrival time could influence growth rates (Huntingford \& Garcia de Leaniz, 1997). Moreover, most of the fish which had the greatest probability of joining the upper modal group and smolting after one year belonged to group 1, and were territorial. This is further evidence, but in the semi-natural setting of an artificial stream, that ability to obtain a preferred feeding station and withstand competition influences the age at which juvenile salmon migrate to sea (Metcalfe, 1989, 1991).

The authors thank V. Cameron for fish husbandry, BOCM Pauls for supplying fish food, and J. Johnsson and an anonymous referee for helpful comments on an earlier draft of the manuscript. The study was carried out whilst CJC was in receipt of a NERC studentship, ref. no.: GT4/92/ALS/168.

\section{References}

Abbott, J. C., Dunbrack, R. L. \& Orr, C. D. (1985). The interaction of size and experience in dominance relationships of juvenile steelhead trout (Salmo gairdneri). Behaviour 92, 241-253. 
Arcese, P. (1989). Territory acquisition and loss in male song sparrows. Animal Behaviour 37, 45-55.

Brännäs, E. (1987). Influence of photoperiod and temperature on hatching and emergence of Baltic salmon (Salmo salar L.). Canadian Journal of Zoology 65, 1503-1508.

Chandler, G. L. \& Bjornn, T. C. (1988). Abundance, growth and interactions of juvenile steelhead trout relative to time of emergence. Transactions of the American Fisheries Society 117, 432-443.

Cutts, C. J., Metcalfe, N. B. \& Taylor, A. C. (1999). Competitive asymmetries in territorial juvenile Atlantic salmon (Salmo salar L.). Oikos, in press.

Dill, L. M. (1978). Aggressive distance in juvenile coho salmon (Oncorhynchus kisutch). Canadian Journal of Zoology 56, 1441-1446.

Egglishaw, H. J. \& Shackley, P. E. (1973). An experiment on faster growth of salmon Salmo salar (L.) in a Scottish stream. Journal of Fish Biology 5, 197-204.

Elliott, J. M. (1984). Numerical changes and population regulation in young migratory trout Salmo trutta in a Lake District stream, 1966-83. Journal of Animal Ecology 53, 327-350.

Elliott, J. M. (1990). Mechanisms responsible for population regulation in young migratory trout, Salmo trutta III: the role of territorial behaviour. Journal of Animal Ecology 59, 803-819.

Fausch, K. D. (1984). Profitable stream positions for salmonids: relating specific growth rate to net energy gain. Canadian Journal of Zoology 62, 441-451.

Fausch, K. D. \& White, R. J. (1986). Competition among juveniles of coho salmon, brook trout, and brown trout in a laboratory stream, and implications for Great Lakes tributaries. Transactions of the American Fisheries Society 115, 363-381.

Glova, G. J. \& Field-Dodgson, M. S. (1995). Behavioural interactions between chinook salmon and brown trout juveniles in a simulated stream. Transactions of the American Fisheries Society 124, 194-206.

Grant, J. W. A. (1990). Aggressiveness and the foraging behaviour of young-of-the-year brook charr (Salvelinus fontinalis). Canadian Journal of Fisheries and Aquatic Sciences 47, 915-920.

Gustavson-Marjanen, K. I. \& Dowse, H. B. (1983). Seasonal and diel patterns of emergence from the redd of Atlantic salmon (Salmo salar) fry. Canadian Journal of Fisheries and Aquatic Sciences 40, 813-817.

Harvey, P. H., Stenning, M. J. \& Campbell, B. (1985). Individual variation in seasonal breeding success of pied flycatchers (Ficedula hypoleuca). Journal of Animal Ecology 53, 727-736.

Hughes, N. F. (1992). Ranking of feeding positions by drift-feeding Arctic grayling (Thymallus articus) in dominance hierarchies. Canadian Journal of Fisheries and Aquatic Sciences 49, 1994-1998.

Huntingford, F. A. \& Garcia de Leaniz, C. (1997). Social dominance, prior residence and the acquisition of profitable feeding sites in juvenile Atlantic salmon. Journal of Fish Biology 51, 1009-1014.

Huntingford, F. A. \& Turner, A. K. (1987). Animal Conflict. London: Chapman \& Hall.

Jenkins, T. M. (1969). Social structure, position choice and microdistribution of two trout species (Salmo trutta and Salmo gairdneri) resident in mountain streams. Animal Behaviour Monographs 2, 57-123.

Johnsson, J. I., Nöbbelin, F. \& Bohlin, T. (1999). Territorial competition among wild brown trout fry: effects of ownership and body size. Journal of Fish Biology 54, 469-472.

Mason, J. C. \& Chapman, D. W. (1965). Significance of early emergence, environmental rearing capacity and behavioural ecology of juvenile coho salmon in stream channels. Journal of the Fisheries Research Board of Canada 22, 173-191.

Maynard Smith, J. (1974). Models in Ecology. Cambridge: Cambridge University Press. 
Metcalfe, N. B. (1989). Differential response to a competitor by Atlantic salmon adopting alternative life history strategies. Proceedings of the Royal Society of London B 236, 21-27.

Metcalfe, N. B. (1991). Competitive ability influences seaward migration age in Atlantic salmon. Canadian Journal of Zoology 69, 815-817.

Metcalfe, N. B. \& Thorpe, J. E. (1990). Determinants of geographical variation in age of seaward-migrating salmon, Salmo salar. Journal of Animal Ecology 59, 135-145.

Metcalfe, N. B. \& Thorpe, J. E. (1992). Early predictors of life-history events: the link between first feeding date, dominance and seaward migration in Atlantic salmon, Salmo salar. Journal of Fish Biology 41 (Suppl. B), 93-99.

Metcalfe, N. B., Huntingford, F. A., Graham, W. D. \& Thorpe, J. E. (1989). Early social status and the development of life-history strategies in Atlantic salmon. Proceedings of the Royal Society of London B 236, 7-19.

Metcalfe, N. B., Huntingford, F. A., Thorpe, J. E. \& Adams, C. E. (1990). The effects of social status on life-history variation in juvenile salmon. Canadian Journal of Zoology 68, 2630-2636.

Puckett, K. S. \& Dill, L. M. (1985). Energetics of feeding territoriality in juvenile coho salmon. Behaviour 92, 97-111.

Slagsvold, T., Lifjeld, J. T., Stenmark, G. \& Breiehagen, T. (1988). On the cost of searching for a mate in female pied flycatchers Ficedula hypoleuca. Animal Behaviour 36, 433-442.

Stamps, J. A. \& Krishnan, V. V. (1994). Territory acquisition in lizards: I. First encounters. Animal Behaviour 47, 1375-1385.

Thorpe, J. E. (1977). Bimodal distribution of length of juvenile Atlantic salmon under artificial rearing conditions. Journal of Fish Biology 11, 175-184.

Thorpe, J. E. (1989). Developmental variation in salmonid populations. Journal of Fish Biology 35, 295-303. 